\title{
Complete right bundle-branch block Echophonocardiographic study of first heart sound and right ventricular contraction times
}

\author{
NICHOLAS BROOKS ${ }^{1}$, GRAHAM LEECH ${ }^{2}$, AND AUBREY LEATHAM
}

From St George's Hospital, London

SUMMARY High speed echocardiograms of the mitral, tricuspid, and pulmonary valves were recorded with a simultaneous electrocardiogram and phonocardiogram in 20 patients with complete right bundlebranch block and in 67 normal subjects. Late opening of the pulmonary valve indicating late right ventricular ejection was found in all patients. In 8 patients with wide splitting of the first heart sound the late ejection was related mainly to delay in tricuspid valve closure, suggesting a late onset of the right ventricular pressure pulse. In 10 patients with a single first heart sound the delayed ejection was associated with a long interval between tricuspid valve closure and pulmonary valve opening, suggesting a slow rising right ventricular pressure pulse; 3 of these patients also had late tricuspid valve closure but the tricuspid component of the first sound was absent. Late onset of pressure rise is thought to result from block in the main right bundle-branch, and a slow rising pulse from block in the distal Purkinje network. These findings explain the conflicting results in previous studies of the first heart sound and right ventricular pressure pulse in patients with right bundle-branch block, and may have prognostic significance.

The finding of right bundle-branch block as an isolated electrocardiographic abnormality raises difficult prognostic problems, particularly in aviation and life assurance medicine, since the pathological basis and risk of progression to complete atrioventricular block are unknown. Differentiation of proximal block caused by disruption of the main bundle-branch, from peripheral (arborisation) block in which the disruption is in the distal Purkinje network, might well have considerable significance, but cannot be made on the electrocardiogram (Oppenheimer and Rothschild, 1917; Wolferth and Margolies, 1935; Rosenman et al., 1950; AlzamoraCastro et al., 1953). An attempt has therefore been made to obtain this information by studying the effect of complete right bundle-branch block on contraction times. Cardiac catheterisation with catheter tip manometers and analysis of pressure pulses is seldom justifiable in subjects with isolated

\footnotetext{
${ }^{1}$ British Heart Foundation Junior Research Fellow. 'British Heart Foundation Senior Research Fellow. Received for publication 7 September 1978
}

conduction disturbances, and the findings cannot be applied to patients with abnormal haemodynamics. Abnormally wide splitting of the second heart sound from late pulmonary valve closure is found in right bundle-branch block with a QRS duration of 120 ms or more (Haber and Leatham, 1965) and wide splitting of the first heart sound caused by delayed tricuspid closure should be a useful sign of a late onset of the right ventricular pressure pulse. Identification of the components of the first sound is sometimes uncertain however, and furthermore the isovolumic contraction period and moment of ejection cannot be recorded in the absence of an ejection sound.

High resolution echophonocardiography which permits exact timing of mitral and tricuspid valve closure and aortic and pulmonary valve opening (Leatham and Leech, 1975; Waider and Craige, 1975) can now be used to study mechanical events on each side of the heart. We report the use of this technique to analyse the mechanism of delay in subjects with complete right bundle-branch block in whom resting haemodynamics were thought to be normal. 


\section{Patients and methods}

There were 20 patients aged 11 to 74 in whom electrocardiograms showed a slurred ' $s$ ' wave in leads 1 and V7, and a secondary ' $R$ ' deflection in the right praecordial leads but in whom there was no evidence of pulmonary hypertension or cardiac failure. The QRS duration varied between 120 and $200 \mathrm{~ms}$ and the PR interval from 120 to $190 \mathrm{~ms}$.

Sixty-seven normal volunteers, 27 men and 40 women aged 19 to 56 , served as controls.

The subjects were studied with the trunk raised approximately 30 degrees and tilted to the left when this was necessary to obtain satisfactory recordings. The echocardiogram was recorded on a Smith Kline ultrasonoscope using a $2 \cdot 25 \mathrm{MHz}$ focused transducer with pulse repetition frequency increased to 2000/s. The output was displayed on a Cambridge six-channel recorder modified to improve echo depth magnification and with maximum paper speed increased to $200 \mathrm{~mm} / \mathrm{s}$. The standard lead electrocardiogram showing the earliest QRS onset was recorded simultaneously, together with a high frequency phonocardiogram from the lower left sternal edge unless it interfered with placement of the echo transducer in which case it was recorded separately. All recordings were made with maximum magnification of the echo display and at a paper speed of $200 \mathrm{~mm} / \mathrm{s}$.

The mitral valve was identified by the standard technique and recorded to show its moment of closure, defined as the point of complete apposition of the anterior and posterior cusps. The ultrasound beam was then angled medially to identify the characteristic movement of the anterior leaflet of the tricuspid valve. In order to visualise the point of cusp apposition, however, it is necessary to direct the transducer inferiorly until nearly all of the anterior leaflet echoes have disappeared. This manoeuvre usually enables a small part of both the anterior and posterior leaflets to be visualised as they meet and form the systolic closure line. The typical appearance is shown in Fig. 1. Sometimes two cusps cannot be visualised at the same time and in such cases we have found that the best definition of valve closure is obtained from the posterior (septal) cusp which shows a sharply defined 'shoulder' as it abruptly changes direction. Fig. 2 is the tricuspid valve echo from the same subject as Fig. 1 and shows this appearance. Note that in both views valve closure coincides exactly with the beginning of the second high frequency component of the first heart sound (T1). Finally, the posterior pulmonary valve cusp was located by pointing the transducer superiorly and laterally from the aortic root position, and a recording was made to show the full extent of its opening movement.

Whenever possible recordings were made in shallow held expiration (taking care to prevent the patient from performing a Valsalva manoeuvre), but in a number of cases the points of interest on the echocardiogram were visible only during other phases of the respiratory cycle. We have, however, made a number of recordings during continuous respiration and, surprisingly, the timing of mitral and tricuspid closure and complete pulmonary opening do not vary appreciably in normal subjects.

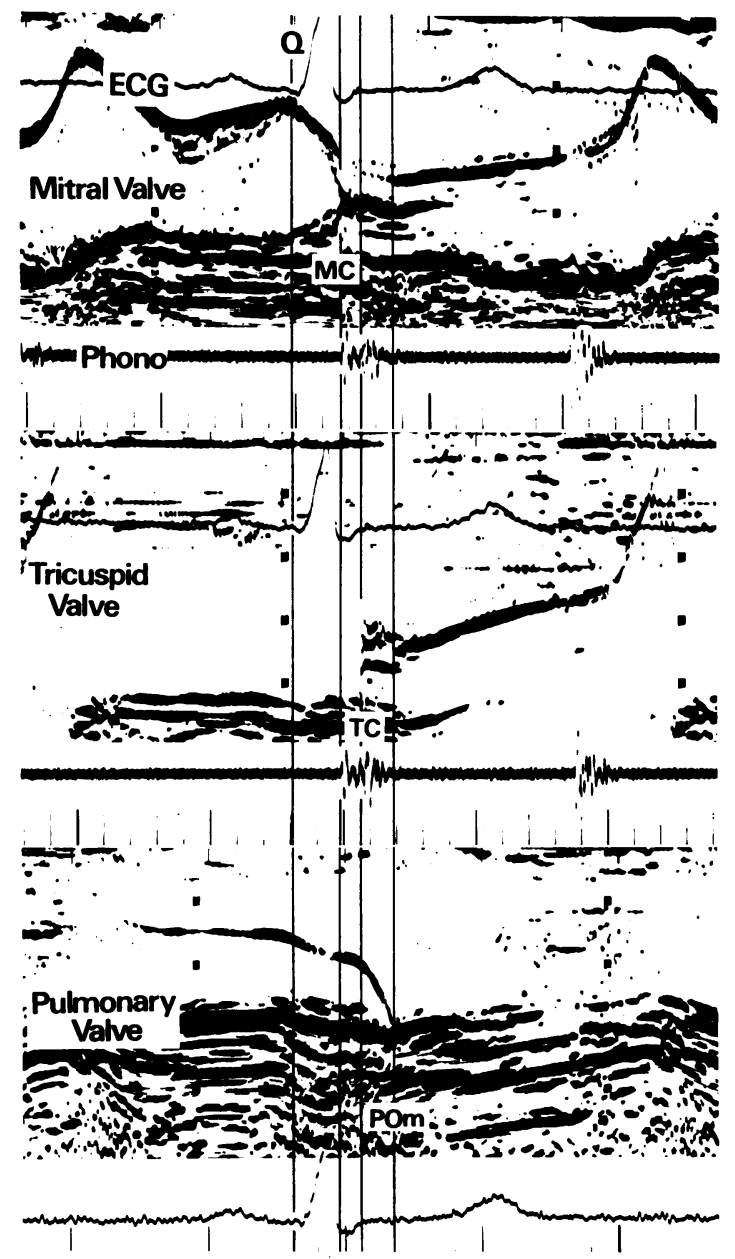

Fig. 1 Echocardiograms of the mitral, tricuspid, and pulmonary valves with a simultaneous electrocardiogram and phonocardiogram from a normal subject. The recordings have been aligned on the $Q$ wave of the electrocardiogram to illustrate the measurements. $M C$, mitral valve closure; TC, tricuspid valve closure; POm, complete pulmonary valve opening; time lines, $40 \mathrm{~ms}$. 


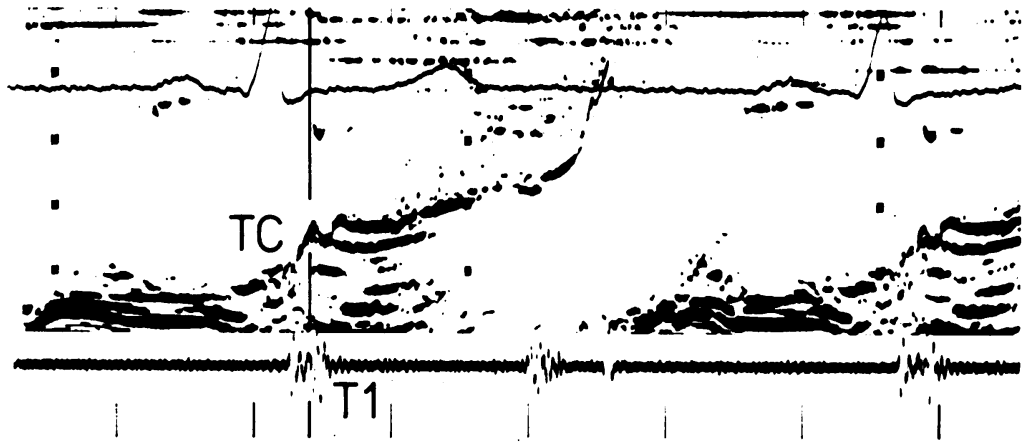

Fig. 2 Tricuspid valve echocardiogram with simultaneous phonocardiogram from the same subject as in Fig. 1, but showing only the posterior valve cusp at the point of closure.

\section{MEASUREMENTS}

Time intervals were measured to the nearest $0.5 \mathrm{~mm}$ (equivalent to $2.5 \mathrm{~ms}$ ) using a hair-line cursor on a special measuring device. A correction was made for variations in paper speed by measuring the time between six $0.2 \mathrm{~s}$ markers. If electrocardiographic noise made it difficult to identify the $q$ wave in an individual beat, measurements were made from the $\mathbf{R}$ wave and the $q$ to $\mathbf{R}$ time was added. In each recording 5 cardiac cycles were averaged. The following intervals were measured:

(1) Onset of the initial deflection of the QRS complex of the electrocardiogram to mitral valve closure (Q-MC).

(2) Onset of QRS to tricuspid valve closure (Q-TC).

(3) Onset of QRS to maximal opening of the pulmonary valve (Q-POm).

The onset of pulmonary opening was not used for measurement because it is impossible to define this point precisely when only one valve cusp can be visualised. For this reason the point of complete opening was taken. This is often marked by a definite 'shoulder' at which point its posterior movement is arrested and the cusp begins to move in an anterior direction. When this shoulder was not seen the full posterior extent of the pulmonary valve echo was used.

Q-MC was subtracted from Q-TC to give the interval between mitral and tricuspid valve closure (MC-TC), and Q-TC from Q-POm to derive the interval from tricuspid closure to pulmonary opening (TC-POm). The estimation of these intervals is illustrated in Fig. 1 which is a set of recordings from a subject with normal intraventricular conduction.

\section{Results}

\section{(1) 67 NORMAL SUBJECTS}

The mean Q-MC, Q-TC, MC-TC, Q-POm, and TC-POm intervals in the normal subjects are summarised in Table 1 , and the mean and normal ranges (mean \pm twice the standard deviation) of
Table 1 Results

\begin{tabular}{|c|c|c|c|c|c|}
\hline Normal subjects & $\underset{(m s)}{Q-M C}$ & $\underset{(m s)}{Q-T C}$ & $\begin{array}{l}M C-T C \\
(m s)\end{array}$ & $\underset{(m s)}{Q-P O m}$ & $\begin{array}{l}T C-P O m \\
(m s)\end{array}$ \\
\hline $\begin{array}{l}\text { Mean } \\
\text { Standard deviation } \\
\text { Standard error of }\end{array}$ & $\begin{array}{l}54 \cdot 5 \\
11 \cdot 0\end{array}$ & $\begin{array}{l}87 \cdot 0 \\
16 \cdot 6\end{array}$ & $\begin{array}{l}33 \cdot 8 \\
10 \cdot 5\end{array}$ & $\begin{array}{r}126 \cdot 4 \\
14 \cdot 3\end{array}$ & $\begin{array}{l}38 \cdot 6 \\
12 \cdot 2\end{array}$ \\
\hline $\begin{array}{l}\text { mean } \\
\text { No. }\end{array}$ & $67^{1 \cdot 3}$ & $\begin{array}{c}2 \cdot 1 \\
63\end{array}$ & 63 & $\begin{array}{c}2 \cdot 1 \\
47\end{array}$ & $\begin{array}{c}1 \cdot 8 \\
46\end{array}$ \\
\hline
\end{tabular}

Right bundle-

branch block

Group 1-Split S1

$\begin{array}{llllll}\text { (1) Isolated RBBB } & 60 & 126 & 66 & 175 & 49\end{array}$

$\begin{array}{llllll}\text { (2) Isolated RBBB } & 80 & 140 & 60 & 203 & 63\end{array}$

$\begin{array}{llllll}\text { (3) Isolated RBBB } & 58 & 117 & 59 & 161 & 44\end{array}$

$\begin{array}{llllll}\text { (4) Isolated RBBB } & 70 & 125 & 55 & 178 & 53\end{array}$

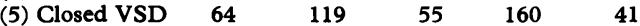

$\begin{array}{llllll}\text { (6) Closed ASD } & 66 & 136 & 70 & 189 & 53\end{array}$

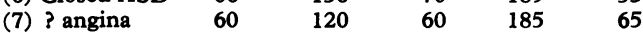

(8) SA node disease $50 \quad 102 \quad 52 \quad 172 \quad 70$

Means

\begin{tabular}{lllll}
\hline 63.5 & 123.1 & 59.6 & 177.9 & 54.8
\end{tabular}

Group 2-Single S1

(9) Intermittent

$\begin{array}{llllll}\text { CHB } & 65 & 87 & 22 & 181 & 94\end{array}$

$\begin{array}{clllll}\text { CHB } & 75 & 95 & 20 & 172 & 77\end{array}$

$\begin{array}{llllll}\text { (11) Anterior in- } & & & & & \\ \text { farct; LAD } & 50 & 70 & 20 & 160 & 90\end{array}$

(12) Angina; LAD; intermittent $\begin{array}{llllll}\text { CHB } & 88 & 98 & 10 & 233 & 135\end{array}$

$\begin{array}{lllllr}\text { (13) Angina } & 84 & 118 & 34 & 186 & 68\end{array}$

$\begin{array}{llllll}\text { (14) Mild AS; } & & & & & \\ \text { LAD } & 50 & 85 & 35 & 171 & 86\end{array}$

$\begin{array}{cccccc}\begin{array}{c}\text { (15) Healed myo- } \\ \text { carditis }\end{array} & 60 & 81 & 21 & 160 & 79\end{array}$

(16) Intermittent
CHB; LAD 41 $\quad 94 \quad 53 \quad 183 \quad 89$

$\begin{array}{llllll}\text { (17) LAD } & 53 & 135 & 72 & 210 & 75\end{array}$

(18) LAD ? cardio\begin{tabular}{llllll} 
myopathy & 45 & 100 & 55 & 197 & 97 \\
\cline { 2 - 6 } & $61 \cdot 1$ & $96 \cdot 3$ & $34 \cdot 2$ & $185 \cdot 3$ & $89 \cdot 0$
\end{tabular}

Means

$\begin{array}{lllll}61 \cdot 1 & 96 \cdot 3 & 34 \cdot 2 & 185 \cdot 3 & 89 \cdot 0\end{array}$

Absent $S 1$

(19) Obese; ant. infarct; $\begin{array}{llllll}\text { LAD } & 48 & 101 & 53 & 166 & 65\end{array}$

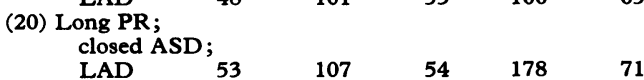

VSD, ventricular septal defect; ASD, atrial septal defect; $C H B$, complete heart block; LAD, left axis deviation; AS, aortic stenosis. 


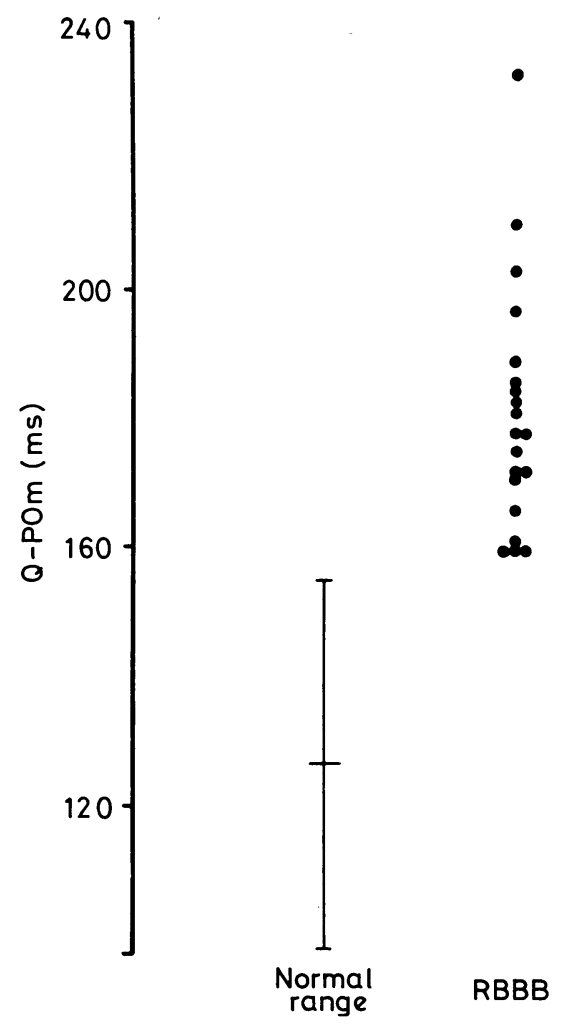

Fig. 3 The timing of pulmonary valve opening in patients with right bundle-branch block compared with the normal range (mean \pm 2 standard deviations).

Q-POm, MC-TC, and TC-POm are shown in Fig. 3, 4, and 5. There was no significant correlation between MC-TC and the PR interval.

In all subjects with a PR interval of less than $180 \mathrm{~ms}$ the onset of the first high frequency component of the first heart sound coincided exactly with mitral valve closure on the echo. Whenever tricuspid valve closure was more than 20 to $30 \mathrm{~ms}$ after mitral closure, it occurred synchronously with a second high frequency component (T1). At shorter MC-TC intervals it was not possible to distinguish two separate components of the sound. At PR intervals longer than $180 \mathrm{~ms}$ the first sound was often absent or represented solely by vibrations coincident with tricuspid closure. These findings will be reported in detail elsewhere.

\section{(2) 20 PATIENTS WITH COMPLETE RIGHT BUNDLE-BRANCH BLOCK}

\section{Pulmonary valve opening}

Complete pulmonary valve opening was delayed in the patients with right bundle-branch block. The

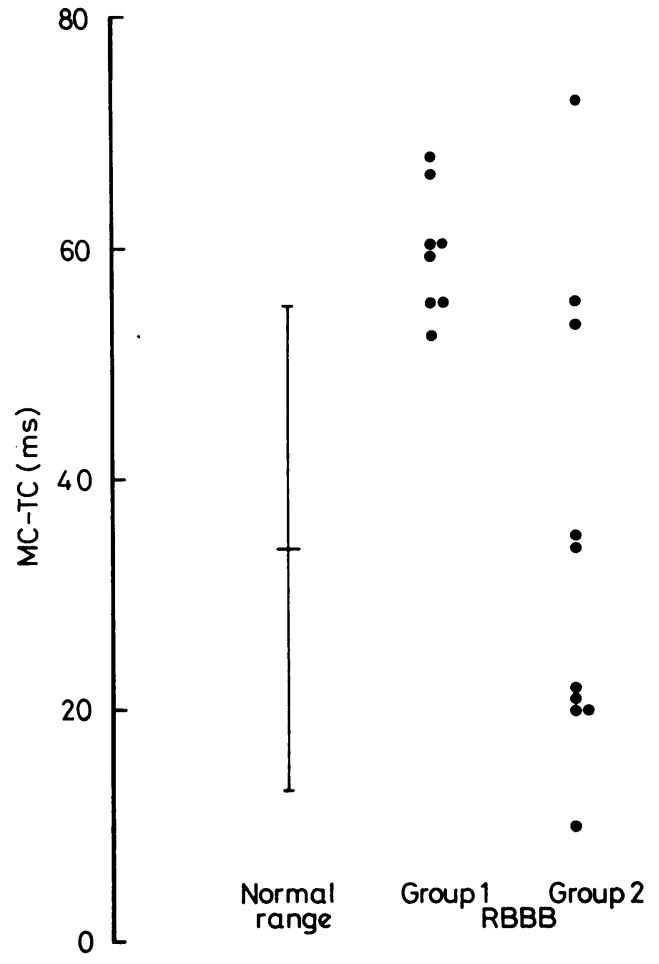

Fig. $4 M C-T C$ in the two groups of patients with right bundle-branch block in comparison with the normal range.

Q-POm interval exceeded two standard deviations above the normal mean in every case and the mean value was $181.0 \mathrm{~ms}$, $55 \mathrm{~ms}$ longer than normal. These findings are illustrated in Fig. 3.

\section{Timing of tricuspid valve closure}

The timing of tricuspid valve closure can be assessed from either the MC-TC or from the Q-TC interval. Mean MC-TC was $46.3 \mathrm{~ms}$, which is only $12.5 \mathrm{~ms}$ longer than the mean value in the normal subjects, but individual results ranged widely from 10 to $70 \mathrm{~ms}$. Similarly, the mean Q-TC interval was $107.8 \mathrm{~ms}, 20.8 \mathrm{~ms}$ longer than normal and ranged from $70 \mathrm{~ms}$ (well within the normal range) to $140 \mathrm{~ms}$ (20 $\mathrm{ms}$ above the upper limit of normal).

Interval from tricuspid closure to pulmonary opening The mean TC-POm interval was $73.2 \mathrm{~ms}$, which is $34.6 \mathrm{~ms}$ longer than the mean value of the control subjects, a difference that is highly significant $(\mathbf{P}<0.01)$, but as with the timing of tricuspid closure there was considerable individual variation from those well within the normal range up to those $72 \mathrm{~ms}$ above its upper limit. 


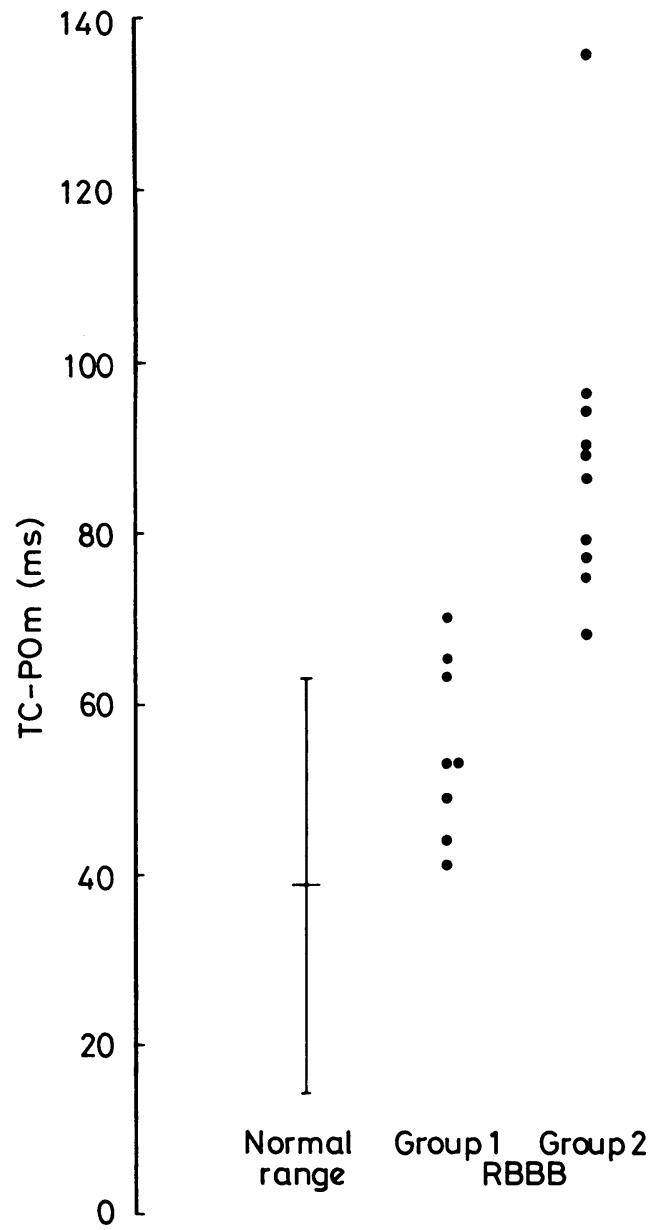

Fig. 5 TC-POm in the two groups of patients with right bundle-branch block in comparison with the normal range.

\section{First heart sound}

In 8 patients the first heart sound was widely split. This was easily detected by auscultation and confirmed by the phonocardiogram. Ten patients had a single first sound and the echophonocardiogram showed that this began at the moment of mitral valve closure. In 5 of these patients tricuspid closure followed mitral closure by more than $30 \mathrm{~ms}$ but did not produce an audible or recordable sound. One patient (case 20) had no detectable first sound in association with a long PR interval and in another the sound was muffled by obesity.

It was very striking that all 4 patients with right bundle-branch block and no other evidence of cardiovascular disease ('isolated right bundle-branch block') had a widely split first sound while the finding of a single first sound was in most cases associated with evidence of more extensive disease of the conducting system. We divided the patients into two groups on the basis of their first sounds: group 1 consisted of 8 patients with a widely split first sound and group 2 of 10 patients with a single sound. The echocardiographic time intervals were then compared.

\section{$Q-P O m$}

Mean Q-POm in group 1 was $177.9 \mathrm{~ms}$ and in group 2 it was $185.3 \mathrm{~ms}$. The difference between the two groups is not statistically significant $(\mathrm{P}>0 \cdot 20)$.

\section{$Q-T C$ and $M C-T C$}

Mean Q-TC in group 1 was $123.1 \mathrm{~ms}$. This is significantly longer than both the group 2 value of $96.3 \mathrm{~ms}$ and the normal mean of $87.0 \mathrm{~ms}(P<0.01$ in both cases). The difference between group 2 and the normals is not significant.

Mean MC-TC in group 1 was $59.6 \mathrm{~ms}$ : this too is significantly longer than the normal subjects $(33.8 \mathrm{~ms})$ and group $2(34.2 \mathrm{~ms})$ at the 1 per cent level. The small difference between the normals and group 2 could have arisen by chance.

The individual MC-TC intervals are shown in Fig. 4. Though the mean value for group 2 was not significantly different from normal, it can be seen that the interval exceeded, or was very close to the upper limit of the normal range, in 3 patients (cases 16,17 , and 18). In cases 16 and 18 this delay in tricuspid closure was not apparent when timed from the electrocardiographic $Q$ wave (Q-TC).

\section{Interval from tricuspid closure to pulmonary opening} The mean TC-POm interval was $54.8 \mathrm{~ms}$ in group 1 and $89.0 \mathrm{~ms}$ in group 2. The difference between groups 1 and 2, and between both patient groups and the normal subjects was highly significant ( $P<0.01$ in all cases). In other words the longest mean TC-POm was in group 2 but that for group 1 was also significantly longer than normal. These results are shown in Fig. 5.

\section{SUMMARY OF RESULTS}

The findings in the two clinical groups may be summarised as follows (Table 2):

Table 2

\begin{tabular}{lllll}
\hline First sound & $\begin{array}{l}\text { Pulmonary } \\
\text { opening }\end{array}$ & $\begin{array}{l}\text { Tricuspid } \\
\text { closure }\end{array}$ & $\begin{array}{l}\text { Tricuspid } \\
\text { closure to } \\
\text { pulmonary } \\
\text { opening }\end{array}$ \\
\hline Group 1 & Wide split & Late & Late & Slightly long \\
Group 2 & Single & Late & $\begin{array}{l}\text { Normal or } \\
\text { late }\end{array}$ & Long \\
\hline
\end{tabular}




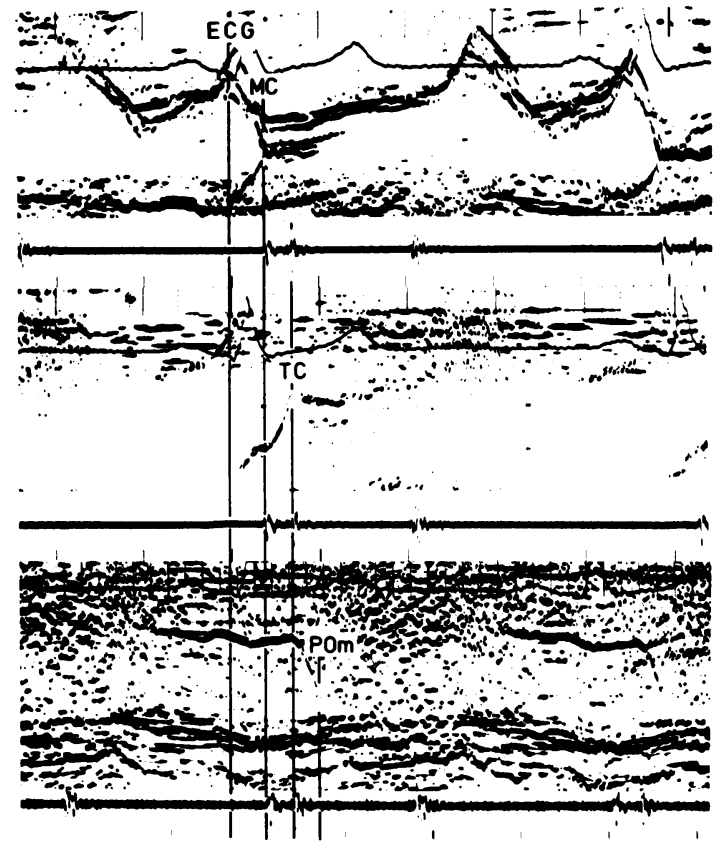

Fig. 6 Echo and phonocardiograms displayed as in Fig. 1 from a patient in group 1 (case 2) with isolated right bundle-branch block. Tricuspid closure is late, the first sound widely split, and the TC-POm interval slightly longer than normal.

The results from the 2 patients with inaudible first sounds are given in Table 1 . In both the MC-TC interval exceeded $50 \mathrm{~ms}$ and TC-POm was above the normal range.

Typical echo and phonocardiograms are illustrated in Fig. 6, 7, and 8.

\section{CLINICAL DETAILS}

In 4 of the group 1 patients right bundle-branch block was the only abnormal finding ('isolated right bundle-branch block'). Two patients, cases 5 and 6 , had surgically corrected congenital heart disease; in both the right bundle-branch block was present before operation. Case 8 had sinuatrial node disease and case 7 had atypical chest pain thought possibly to be angina.

None of the group 2 patients had right bundlebranch block as an isolated finding. Four had episodes of intermittent complete heart block; during conducted rhythm 2 of these had right bundle-branch block and a normal frontal plane QRS axis and 2 had left axis deviation consistent with a diagnosis of additional left anterior hemiblock. Four other patients also had right bundlebranch block with left anterior hemiblock. Case 13

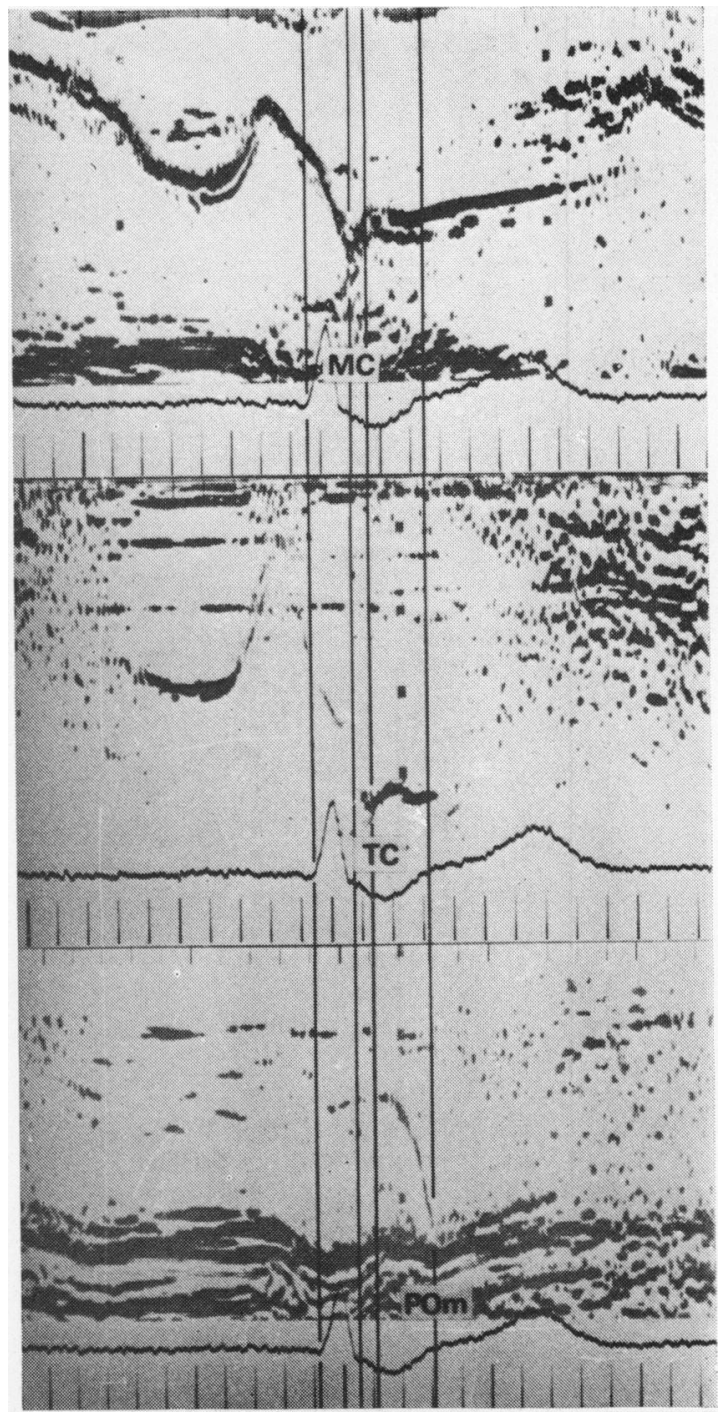

Fig. 7 Echocardiograms displayed as in Fig. 1 from a patient in group 2 (case 11). Tricuspid valve closure is at the normal time $(M C-T C=20 \mathrm{~ms})$ but the TC-POm interval is prolonged.

had angina pectoris. Case 15 developed right bundlebranch block during a presumed viral myocarditis 2 years before; at the time of study there was no evidence of residual heart muscle damage. Case 18 had multiple ventricular extrasystoles and was suspected of having a cardiomyopathy, though resting intracardiac pressures were normal and the left ventricular angiogram showed no evidence of a contraction abnormality. 


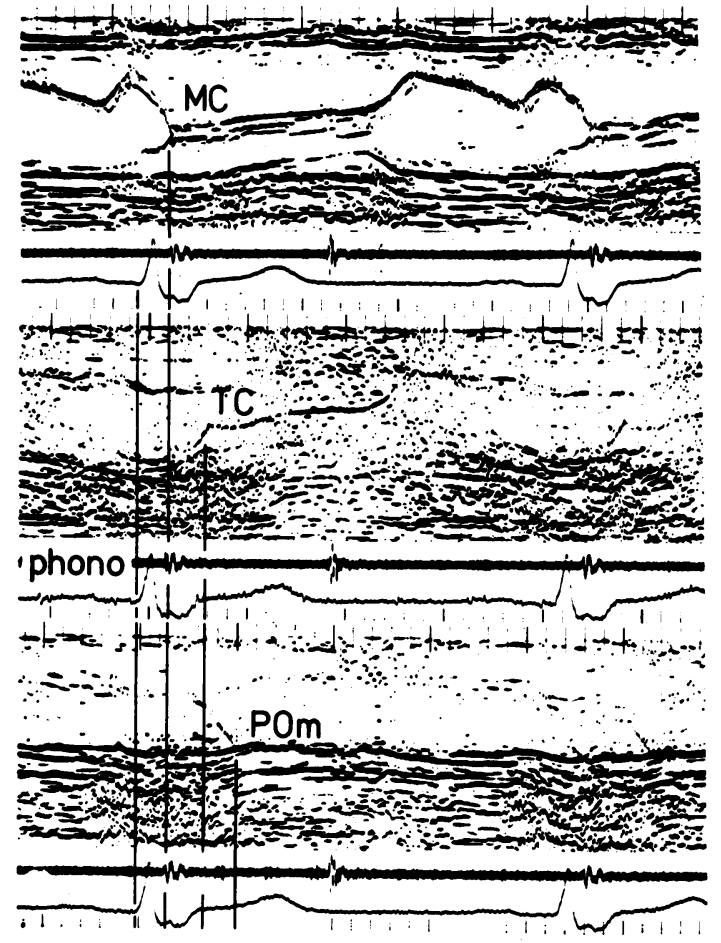

Fig. 8 Echo and phonocardiograms displayed as in Fig. 1 from a patient in group 2 (case 17) with right bundle-branch block and left axis deviation. Tricuspid closure is late (long Q-TC and MC-TC) and TC-POm is lengthened. Despite the late tricuspid closure the first sound is single because $T 1$ is absent.

\section{Discussion}

The mechanical effects of bundle-branch block and their relation to pathological changes in the intraventricular conducting system have been studied for many years. In left bundle-branch block ejection from the left ventricle begins late, in most cases because of prolongation of the isovolumic contraction period, with little or no delay in the onset of contraction (Coblentz et al., 1949; Braunwald and Morrow, 1957; Bourassa et al., 1962; Haber and Leatham, 1965; Adolph et al., 1969). This is consistent with the concept of arborisation block, with the implication that the pathological changes are located in the distal Purkinje network and the main bundle is at least partially intact. Such changes would lead to slow spread of activation through the ventricular myocardium, a reduced rate of pressure development, and consequent lengthening of the isovolumic contraction period.

In right bundle-branch block the invariable delay of the pulmonary component of the second heart sound indicates late termination of right ventricular systole, but there is controversy over the cause of this delay. Leatham and Gray (1956) observed a late onset of the right ventricular pressure pulse and of the tricuspid component of the first heart sound in 6 patients with atrial septal defect and complete right bundle-branch block (but not with incomplete right bundle-branch block) and this was supported by a phonocardiographic study (Haber and Leatham, 1965) in which wide splitting of the first sound (caused by a late tricuspid component) was observed in another group of patients with this conduction disturbance and also with ectopic beats thought to arise from the left ventricle. While observations on heart sounds strongly suggested that tricuspid valve closure, and therefore the onset of the right ventricular pressure pulse, was late in right bundle-branch block, the origin of this sound could not be proved and indeed the whole concept of valve closure as the cause of heart sounds has been challenged (Luisada, 1975). Furthermore, some studies of right bundlebranch block showed absence of delay in some cases (Braunwald and Morrow, 1957). Echocardiograms with simultaneous phonocardiograms, however, showed a loud late component of the first sound coinciding exactly with the final halt of the closing tricuspid valve in Ebstein's anomaly with right bundle-branch block (Crews et al., 1972) and high speed, high definition echocardiography has now established that the initial high frequency component of the first sound coincides with mitral closure and the second component with tricuspid closure (Leatham and Leech, 1975; Waider and Craige, 1975): the normal interval was found to be $30 \mathrm{~ms}$ (Waider and Craige, 1975) which agrees with the $33.8 \pm 1.3 \mathrm{~ms}$ (mean \pm standard error) found in the present study.

Atrioventricular valve closure is normally initiated by atrial contraction and completed by ventricular contraction. A consequence of this is that the timing of mitral and tricuspid valve closure (relative to the onset of electrical depolarisation or ventricular contraction) is determined mainly by the PR interval. Mitral closure occurs before the onset of left ventricular contraction when the $P R$ interval exceeds about 180 and $200 \mathrm{~ms}$ (Zaky et al., 1969; Shah et al., 1970; Burgraff and Craige, 1974); such presystolic closure is usually silent. In a recent study (Brooks et al., 1978) we showed a comparable influence of PR interval on the timing of tricuspid closure, but the effect is weaker than on the mitral valve and presystolic closure does not seem to occur in normal subjects with PR intervals less than $220 \mathrm{~ms}$. MC-TC however was found to be independent of $P R$ interval changes up to about $190 \mathrm{~ms}$, because the effects on the two valves largely cancel 
out. A major factor influencing MC-TC is believed to be the time relation between the onset of contraction of the left and right ventricles. From this we conclude that in the group 1 patients and cases 16 , 17 , and 18 in group 2 the long MC-TC interval is the result of delay in the onset of right ventricular contraction relative to the left, and that in the group 2 patients with normal MC-TC intervals right ventricular contraction begins at the normal time.

The relation of the echo measurement of tricuspid closure to pulmonary valve opening with the early phase of right ventricular contraction must now be discussed. Right ventricular ejection begins at the moment the pulmonary valve starts to open. Therefore the period from tricuspid closure to the onset of pulmonary opening represents the later part of the isovolumic contraction period. By analogy with the left ventricle, the isovolumic contraction period depends on preload, afterload, contractility, and heart rate. In the patients in this study haemodynamics and therefore loading conditions were thought to be normal. No allowance was made for heart rate but there were no extreme variations in either the control or patient groups. Changes in the period from tricuspid closure to onset of pulmonary opening must therefore result mainly from alterations in the rate of right ventricular pressure development $(\mathrm{dP} / \mathrm{dT})$. The period from onset to full opening of the pulmonary valve occurs during the early phase of ejection and it seems reasonable to assume that the time taken for full opening reflects the initial acceleration of blood flow in the pulmonary artery. Provided impedance to ejection is constant this time would also be determined by $\mathrm{dP} / \mathrm{dT}$. Thus it may be concluded that under the conditions of this study changes in TC-POm reflect mainly alterations in the rate of pressure development in the right ventricle.

However, since atrioventricular conduction time affects the timing of tricuspid valve closure (Q-TC) it must also influence the TC-POm interval. In the group 1 patients right ventricular contraction is thought to begin late in which case the time between activation of the right atrium and the right ventricle must be longer than in a normal subject with the same $P R$ interval. The tricuspid valve leaflets will be more closely apposed when right ventricular contraction begins than if contraction had started at the normal time and closure will be completed earlier after the onset of pressure rise than normal. It would be expected therefore that Q-TC and MC-TC would be prolonged by rather less than the delay in the onset of ventricular contraction, and that the difference would be reflected by a slight increase in TC-POm. The findings in group 1 are entirely consistent with this concept; pulmonary valve opening was delayed by an average of $51.5 \mathrm{~ms}$, MC-TC by $25.8 \mathrm{~ms}$, and TC-POm by $16.2 \mathrm{~ms}$. In the group 2 patients, however, TC-POm was much longer, on average $50.4 \mathrm{~ms}$ more than normal-and this points to depression of right ventricular $\mathrm{dP} / \mathrm{dT}$ presumably from uncoordinated contraction caused by the conduction disturbance.

Case 19 had indistinct heart sounds because of his thick chest wall, but the echocardiographic intervals -long MC-TC and TC-POm just over normal range-suggest that he has the type of mechanical disturbance believed to exist in the group 1 patients. In case 20 the inaudible first sound was associated with a long PR interval. Mitral closure may have occurred before the onset of left ventricular contraction so that MC-TC cannot reflect the asynchrony of ventricular contraction and it is not possible to assess the type of delay present.

In this study all the patients with right bundlebranch block had evidence of delayed ejection of blood from the right ventricle. It has been argued that there may be a different underlying mechanism in the two clinically distinguishable groups:

(1) Delayed onset of right ventricular contraction with a normal pressure upstroke indicated by a long MC-TC interval and slight lengthening of TC-POm.

(2) Slow rate of rise of right ventricular pressure indicated by a long TC-POm interval. In some of these patients MC-TC was also long, suggesting an additional delay in onset of right ventricular contraction.

Delayed onset of right ventricular contraction with a normal upstroke time suggests that the proximal part of the right bundle is blocked and that the Purkinje network is intact. These findings are comparable to experimental section of the right bundle (Braun-Menendez and Solari, 1937; Smith et al., 1952). The interruption might be congenital in origin or the pathological change could be very localised. Slowing of the right ventricular pressure upstroke suggests diffuse damage to the distal Purkinje network; this can also be induced in the experimental animal (Abildskov et al., 1965; Millar et al., 1970) and its presence suggests more widespread disease.

In the first group with proximal block causing delay in tricuspid closure, wide splitting of the first heart sound caused by a late tricuspid component was present, enabling this diagnosis to be suspected from auscultation. In the second group with a slow rising ventricular pressure the tricuspid component of the first sound was inaudible. This is comparable to the soft mitral closure in left bundle-branch block (Haber and Leatham, 1965; Thompson et al., 1975) and explains the discrepancies between 
previous studies of the first heart sound in right bundle-branch block (Haber and Leatham, 1965; Silie et al., 1973). Thus wide splitting of the first heart sound in a patient with right bundle-branch block suggests that the block is proximal and, provided the $P R$ interval is less than about $180 \mathrm{~ms}$, a single first heart sound results from inability to hear tricuspid closure and favours arborisation block.

The number of patients so far investigated is small, but there is a striking dominance of widespread disease of the conducting tissue culminating in paroxysmal atrioventricular dissociation in group 2 patients thought to have arborisation block, compared with group 1 patients thought to have isolated proximal block, but a longer follow-up is required. In addition the findings in complete right bundlebranch block can be applied to some extent to the vexed problem of deciding the significance of an rSR complex in the right praecordial leads-socalled partial right bundle-branch block-with a QRS less than $120 \mathrm{~ms}$ duration. When associated with atrial septal defect, and therefore indicating right ventricular hypertrophy (Lasser et al., 1951) there is no delay in the loud tricuspid component of the first heart sound and no delay in the onset of the right ventricular pressure upstroke (Leatham and Gray, 1956). The rSR complex usually reverts to normal after closure of the defect confirming that hypertrophy of the right ventricle was the cause. Yet this electrocardiographic pattern often seems indistinguishable from that caused by a minor conduction delay. In this case, however, abnormally wide splitting of the first heart sound caused by delay in the tricuspid component, confirmed by the echo finding of late tricuspid closure, points to a conduction defect rather than to right ventricular hypertrophy.

The work described is part of a study submitted by N.B. to the University of London for the degree of Doctor of Medicine.

\section{References}

Abildskov, J. A., Eich, R. H., Harumi, K., and Smulyan, H. (1965). Observations on the relation between ventricular activation sequence and the hemodynamic state. Circulation Research, 17, 236-247.

Adolph, R. J., Fowler, N. O., and Tanaka, K. (1969). Prolongation of isovolumic contraction time in left bundlebranch block. American Heart fournal, 78, 585-591.

Alzamora-Castro, V., Abugattas, R., Rubio, C., Bouroncle, J., Zapata, C., Santa-Maria, E., Battilana, G., Binder, T., Subiria, R., and Paredes, D. (1953). Parietal focal block: an experimental and electrocardiographic study. Circulation, 7, 108-115.

Bourassa, M. G., Boiteau, G., and Allenstein, B. J. (1962). Hemodynamic studies during intermittent left bundle branch block. American fournal of Cardiology, 10, 792-799. Braun-Menendez, E., and Solari, L. A. (1937). Asyn- chromisme ventriculaire par section des branches ud faisceau de His. Section de la branche droite. Compess Rendus des Séances de la Société de Biologie et de ses Filialet, 124, 251-256.

Braunwald, E., and Morrow, A. G. (1957). Sequence of ventricular contraction in human bundle-branch block. A study based on simultaneous catheterisation of both ventricles. American fournal of Medicine, 23, 205-211.

Brooks, N., Leech, G., and Leatham, A. (1978). Mechanism of influence of PR interval on first heart sound. In Proceedings of the British Cardiac Society and the Swedish Society of Cardiology (abstract). British Heart fournal, 40, 462.

Burgraff, G. W., and Graige, E. (1974). The first heart sound in complete heart block. Phono-echocardiographic correlations. Circulation, 50, 17-24.

Coblentz, B., Harvey, R. M., Ferrer, M. I., Cournand, A., and Richards, D. W., jun. (1949). The relationship between electrical and mechanical events in the cardiac cycle in man. British Heart fournal, 11, 1-22.

Crews, T. L., Pridie, R. B., Benham, R., and Leatham, A. (1972). Auscultatory and phonocardiographic findings in Ebstein's anomaly. Correlation of first heart sound with ultrasonic records of tricuspid valve movement. British Heart Fournal, 34, 681-687.

Haber, A., and Leatham, A. (1965). Splitting of heart sounds from ventricular asynchrony in bundle branch block, ventricular ectopic beats and artificial pacing. British Heart fournal, 27, 691-696.

Lasser, R. P., Brown, E. R., and Grishman, A. (1951). A vectorcardiographic analysis of the $\mathrm{rSR}^{\prime}$ complex of the unipolar chest lead electrocardiogram. American Heart Fournal, 41, 667-686.

Leatham, A., and Gray, I. (1956). Auscultatory and phonocardiographic signs of atrial septal defect. British Heart Fournal, 18, 193-208.

Leatham, A., and Leech, G. (1975). Observations on relation between heart sounds and valve movements by simultaneous echo and phonocardiography (abstract). British Heart fournal, 37, 557.

Luisada, A. A. (1975). 'Tricuspid' component of the first heart sound. In Physiologic Principles of Heart Sounds and Murmurs, pp. 19-26, ed D. F. Leon and J. A. Shaver. American Heart Association Monograph No. 46. The Association, New York.

Millar, K., Burgess, M. J., Abildskov, J. A., and Eich, R. H. (1970). Dependence of intraventricular pressures on activation order before and after experimental Purkinje net block. fournal of Electrocardiology, 3, 51-56.

Oppenheimer, B. S., and Rothschild, M. A. (1917). Electrocardiographic changes associated with myocardial involvement with special reference to prognosis. Fournal of the American Medical Association, 69, 429-431.

Rosenman, R. H., Pick, A., and Katz, L. N. (1950). The electrocardiographic patterns and the localization of intraventricular conduction defects. American Heart Fournal, 40, 845-866.

Shah, P. M., Kramer, D. H., and Gramiak, R. (1970). Influence of the timing of atrial systole of mitral valve closure and on the first heart sound in man. American Fournal of Cardiology, 26, 231-237.

Silie, M., Delahaye, J. P., and Froment, R. (1973). Étude auscultatoire et phonomecanographique des blocs de branche. Archives des Maladies du Coeur et des Vaisseaux, 66, 235-244.

Smith, L. A., Fields, J., Kennamer, R., and Prinzmetal, M. (1952). Studies on the mechanism of ventricular activity. III. Contraction of the ventricles in experimental bundle branch block. American Heart fournal, 44, 231-237.

Thompson, M. E., Shaver, J. A., Leon, D. F., Rerdy, P. S., 
and Leonard, J. J. (1975). Pathodynamics of the first heart sound. In Physiologic Principles of Heart Sounds and Murmurs, pp. 8-18, ed D. F. Leon and J. A. Shaver. American Heart Association Monograph No. 46. The Association, New York.

Waider, W., and Craige, E. (1975). First heart sound and ejection sounds. Echocardiographic and phonocardiographic correlation with valvular events. American fournal of Cardiology, 35, 346-356.

Wolferth, C. C., and Margolies, A. (1935). Asynchronism in contraction of the ventricles in the so-called common type of bundle branch block: its bearing on the determination of the side of the significant lesion and on the mechanism of split first and second heart sounds. American Heart fournal, 10, 425-452.

Zaky, A., Steinmetz, E., and Feigenbaum, H. (1969). Role of atrium in closure of mitral valve in man. American fournal of Physiology, 217, 1652-1659.

Requests for reprints to Dr N. Brooks, Cardiac Department, The London Chest Hospital, Bonner Road, London E2 9JX. 